\title{
Valko-Venäjän protestilla on naisen kasvot
}

Kun valkovenäläinen toimittaja, esseisti ja vuoden 2015 kirjallisuuden nobelisti Svetlana Aleksijevitš julkaisi vuonna 1985 toisen maailmansodan tapahtumia naissotaveteraanien näkökulmasta käsittelevän romaaninsa Sodalla ei ole naisen kasvoja, hän tuskin pystyi kuvittelemaan mitä valkovenäläiset naiset tulisivat vielä todistamaan tai mihin osallistumaan vuonna 2020.

On perusteltua väittää, että Valko-Venäjän vuoden 2020 presidentinvaalien elokuun yhdeksäntenä ja sitä seuranneiden tapahtumien keskiössä ovat naiset. Valkovenäläinen triumviraatti, tai ehkä oikeammin naisjohtajakolmikko, nousi vaalien keskiöön vasta heinäkuussa 2020, sen jälkeen kuin moni miespuolinen vastaehdokas oli suljettu ulos kilpailusta (ks. Ousmanova 2020). Sen muodostavat presidenttiehdokas Svjatlana Tsihanouskaja, joka ryhtyi ehdokkaaksi vangitun miehensä puolesta, sekä Maria Kolesnikova ja Veronika Tsepkalo, jotka liittyivät Tsihanouskajan vaalikampanjaan kun heidän aikaisemmat ehdokkaansa joko vangittiin tai heidän ehdokkuutensa evättiin. Näistä kolmesta naisesta lähti liikkeelle globaali vaatimus rehellisten vaalien puolesta Valko-Venäjällä. He ovat nyt ehdolla Nobelin rauhanpalkinnon saajiksi 2021 (AFP 2020).

Tässä tekstissä pohdin laajemmin naisten asemaa ja roolia valkovenäläisessä yhteiskunnassa. Samalla pyrin avaamaan naisten johtavaa asemaa vaalien jälkeisissä protesteissa, joita nyt kutsutaan muun muassa vallankumoukseksi ihmisarvon puolesta (Belarussian Revolution of Dignity). Muita käytettyjä nimiä ovat Telegram- tai kukkaisvallankumous. Vaatimus ihmisarvon kunnioittamisesta oli läsnä jo Svjatlana Tsihanouskajan presidentinvaalikampanjassa. Hän nousi vastustamaan valtaa ja kehotti kaikkia kansalaisia noudattamaan toimissaan oikeusvaltion periaatteita. Vaalien jälkeen myös kansa yhdistyi moraalisen ja eettisen vaatimuksen ympärille: vääristeltyä vaalitulosta sekä vaalien jälkeen mielenosoittajiin kohdistettua kohtuutonta väkivaltaa vastaan ja ihmisoikeuksien ja oikeudenmukaisuuden puolesta (The PEN pod, 2020). Tämä valkovenäläinen solidaarisuusliike saattoi yhteen yhteiskunnan eri sukupolvet kyseenalaistaen näin väitettä sukupolvien välisen kuilun syvenemisestä (O'Loughlin et al. 2020). Naisten kohdalla kuilun ylittyminen on erityisen selvä, sillä protestiin osallistui näkyvästi eri ikäisiä sekä eri ammatti- ja sosiaalisiin ryhmiin kuuluvia naisia.

Samoin kuin neuvostoaikana, naisten sosiaalinen ja poliittinen edustus nyky-ValkoVenäjällä on nimellistä ja perustuu kiintiöihin. Tästä johtuen vaalikampanjan alussa maan 
valtaapitävät eivät nähneet Svjatlana Tsihanouskajaa, korkeasti koulutettua kotiäitiä, mitenkään vakavasti otettavana poliittisena vastustajana. Tsihanouskaja lähtikin mukaan vaaleihin "sortavan poliisikoneiston" (Gapova 2020) toimien seurauksena, jolle keskeistä on kohdistaa huomionsa vain miehiin ja kohdella naisia vaarattomina figuureina, joilta puuttuu ääni ja asema vanhoillispatriarkaalisessa yhteiskunnassa. Tsihanouskajan kampanja kasvatti kuitenkin nopeasti julkista kannatusta ja muodostui hallinnon vastaisten protestiäänien kanavaksi, mikä tarjosi myös toivon häivähdyksen poliittisen muutoksen mahdollisuudesta. Tämän lisäksi Tsihanouskaja edusti "uutta, vapautunutta, urbaania, koulutettua ja sosiaalisesti ja kulttuurisesti moninaista Valko-Venäjää”, joka seuraa mieluummin globaalia digitaalista mediaa kuin jäykkää, patriarkaalista, analogista ja television voimaan tukeutuvaa hallintoa (Ousmanova 2020). Pikkuhiljaa Tsihanouskaja muuttui poliittisia tavoitteita vailla olevasta "teknisestä ehdokkaasta" naispuoliseksi poliittinen johtajaksi.

Uuden median kuten Telegrammin ja muiden some-kanavien merkitystä on tutkittu paljon kuluneen vuosikymmenen aikana tapahtuneiden vallankumousten yhteydessä (esim. Bush 2020; Herasimenka 2020), mutta jo neuvostohistorialle keskeisen nk. "naiskysymyksen" (zenski vopros) merkityksen avaaminen Valko-Venäjän protestiliikkeen kontekstissa vaatii monipuolisempaa ja hienojakoisempaa analyysia. Brittiläinen The Guardian käytti ilmaisua"flower power", kun se viittasi protestiin osallistuneiden naisten muodostamiin rauhanomaisiin ihmisketjuihin tai lauantaisin järjestettyihin naisten marsseihin, joissa naiset kukat käsissään muodostuivat vaalien jälkeisen brutaalin väkivallan uhreille osoitettavan solidaarisuuden symboliksi. ${ }^{1}$ Tämä oli solidaarisuuden merkki paitsi protestin muille osallistujille, myös koko Valko-Venäjän yhteiskunnalle. Ehkä juuri kukkien viehättävyys ja

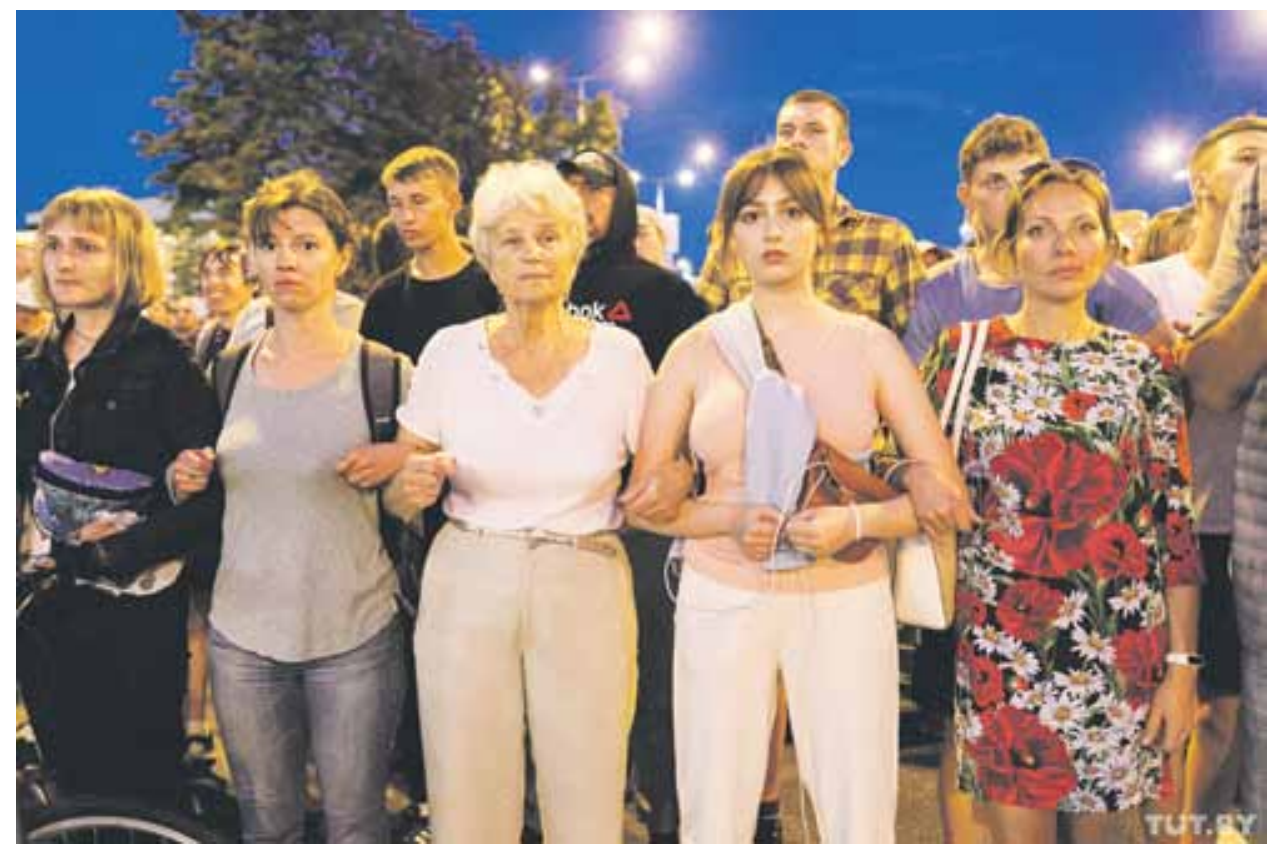

Naiset seisovat mellakkapoliisin edessä Pieramozhcau-kadulla Minskin keskustassa pidetyssä mielenosoituksessa, jossa protestoitiin presidentinvaalien tulosta vastaan 10.8.2020. Kuva: Volha Shukaila / TUT.BY. 
hauraus alleviivaavat sitä yhtäaikaisen kauneuden ja rohkeuden vaikutelmaa, joka syntyy kun eri ikäiset naiset yhdessä marssivat avoimesti kaduilla eri kaupungeissa. Tämä naisten näkyvyys julkisessa tilassa, mikä ilmaistiin mielenosoituksissa niin kukkien kuin myös valkoisten vaatteiden, protestin lippuun viittaavien puna-valko-punaisten sateenvarjojen, banderollien ja verbaalisten huutojen välityksellä, viittaa siihen mitä Frisken (2000) kutsuu "julkiseksi naiseudeksi" (public womanhood). Tämä ei tarkoita, että kaikki mielenosoituksiin osallistuvat naiset tunnustautuisivat feministeiksi, tai että he olisivat syvästi poliittisia. Samaan aikaan he kuitenkin osallistuvat aktiivisesti julkiseen toimintaan (Gapova 2020) ja puhuvat omasta voimaantumisestaan, kasvavasta solidaarisuudesta sekä optimismista (From Silence to Voice, webinar 2020). Ennen kaikkea naisten yhteisyydestä julkisessa tilassa tuli symboli atomisoituneen jälkineuvostoliittolaisen yhteiskunnan muutoksesta kohti integroitua kokonaisuutta.

Naiset ovat toimineet usein muutoksen katalysaattoreina historian eri aikoina. Monien esimerkkien joukosta, joissa naisten rauhanomainen mutta sitkeä autoritaarisen hallinnon vastustus on saanut aikaan muutoksen, voi nostaa Argentiinan Toukokuun aukion äidit (Madres de Plaza de Mayo) (1977-2006) tai Puolan solidaarisuusliikkeen ja Anna Walentynowiczin roolin Gdańskin lakossa (Katz 2020). Valko-Venäjällä 37-vuotias Tsihanouskaja on vain yksi protestin symboli. Myös 73-vuotiaasta hauraanoloisesta eläkeläisestä Nina Baginskajasta, joka nähtiin askeltamassa Minskin katuja ja heiluttamassa lippua päänsä yläpuolella, tuli inspiraationlähde niin katutaiteelle, internetissä julkaistuille kuville, kuin myös kansainväliselle yleisölle, joka näki hänen kuvansa Voguessa. ${ }^{2}$ Yhdistämällä tämä tavallisten (joskin jo julkkisstatuksen saavuttaneiden) valkovenäläisnaisten osallistuminen protestiliikkeeseen niiden naisten toimintaan, joilla jo on merkittävä sosiaalinen pääoma, kuten esimerkiksi jo mainitulla Svetlana Aleksijevitšilla ${ }^{3}$, on mahdollista muodostaa käsitys naisten laajamittaisesta omistautumisesta poliittiselle muutokselle Valko-Venäjällä.

Tämä osallistuminen ei ole puhtaasti feminististä, mutta se ei myöskään edusta tai edistä patriarkaalisia rakenteita. Vaikka valkovenäläiset, etenkin nuoremman polven edustajat, ovat vuorovaikutuksessa ulkomaisten kulttuurien kanssa (Valko-Venäjältä on helppo matkustaa esimerkiksi EU-maihin) ja ovat yhteydessä globaaleihin uutisvirtoihin internetin välityksellä, ${ }^{4}$ naiset Valko-Venäjällä ovat yleisesti ottaen omaksuneet hyvin erityislaatuisen näkökulman tasa-arvokysymyksiin. Se ei ole länsimielinen tai Eurooppa-myönteinen, eikä myöskään puhtaan "feministinen". Jotta ymmärtäisimme paremmin tätä jälkineuvostoliittolaista "post-feminististä" katsantokantaa, on tarpeen kurkistaa lähihistoriaan. Naiset ValkoVenäjällä - EU:n ja Venäjän välissä - elävät samanlaisessa tilanteessa kuin naiset muissa jälkineuvostoliittolaisissa maissa. Neuvostoliiton jättämä "pakotetun tasa-arvon" perintö, Neuvostoliiton jälkeisen ajan murrokset 1990-luvulla ja "uusvanhoillisten" patriarkaalisten arvojen voimakas korostaminen viime aikojen valtion politiikassa ovat johtaneet naisten kohdalla omaleimaiseen itseymmärrykseen suhteessa yhteiskuntaan.

Neuvostojärjestelmä ja nykyisin Valko-Venäjän valtio tukee tietyiltä osin naisten autonomiaa ja sukupuolten välistä tasa-arvoa (esim. äitiysloma, päivähoito, pääsy korkeakoulutukseen, jne.), mutta käytännössä tämä on johtanut monien kohdalla kaksin- tai jopa kolminkertaiseen työtaakkaan: naiset tekevät täysiaikaista työtä, hoitavat työajan ulkopuolella lapset ja kodin sekä pitävät huolta yksityisyrittäjän pieteetillä omasta ulkonäöstään, mikä on naisille tärkeää päöomaa yhteiskunnassa menestymiseen. Valkovenäläiset naiset eivät kuitenkaan pidä itseään alistettuina. He haluavat muodostaa oman agendansa ja ovat siksi osin epäileväisiä länsimaista feminismiä kohtaan, joka tosin usein ymmärretään väärin yhtenä yhtenäisenä liikkeenä. 
Blagojević-Hjuson (2014) kutsuu tätä asennetta "itse/uhrautuvaksi mikro-matriarkaatiksi" (self/sacrificing micro-matriarchy), missä naisilla on merkittävä vaikutusvalta yksityiselämän piirissä, mutta samalla he tekevät erilaisia uhrautuvaisia toimenpiteitä, kuten ottavat ikään kuin luonnollisena heille lankeavan vastuun kodista ja lastenhoidosta.

Itsensä uhraus toisin sanoen tekee mahdolliseksi naisten oikeutuksen autonomisena toimijana uusvanhoillisessa yhteiskunnassa, jossa vallitsee voimakas patriarkaalinen ideologia. Samalla se kuitenkin tuottaa oudon "supernaisen" normin, jossa voimakkuus ja pärjäävyys sekoittuvat uhrautuvuuteen - naisen, joka on enemmän kuin vain tasa-arvoinen. BlagojevićHjuson (2014) ymmärtää kuitenkin tämän itse/uhrautuvan mikro-matriarkaatin olevan "vain väliaikainen vaihe matkalla tasa-arvoisempaan sukupuolijärjestykseen myös yksityisen piirissä” ja näin oikeastaan tietynlainen emansipatorinen strategia (kursiivi-G.M.). Vaikka sukupuolten välistä tasa-arvoa ei aktiivisesti tavoitella politiikan avulla tai sitä ei voi suoranaisesti havainnoida muuallakaan julkisessa tilassa tai edes tasa-arvodiskursseissa, tasa-arvoistavat käytänteet ovat voimistuneet yksityisen piirissä. Viimeaikaiset muutokset valkovenäläisessä sukupuolijärjestelmässä, kuten enenevässä määrin joustavat sukupuolisopimukset (esim. tietoinen yksinhuoltajaäitiys) ja naisten kasvava taloudellinen itsenäisyys ovat johtaneet yhä tasa-arvoisempaan, kumppanuutta korostavaan perhemalliin. Nämä kehityskulut yhdistettynä mahdollisuuteen vielä nojata myös perinteisen yhteiskunnan rakenteisiin (esimerkiksi isovanhempien tukeen) ovat esimerkkejä käytänteistä, jotka kiihdyttävät naisten voimaantumista ja mahdollistavat heidän näkyvän roolinsa myös yksityisen "semiperiferian" ulkopuolella.

Vallanpitäjien patriarkaalinen diskurssi ja sen käsitys naisista epäitsenäisinä avainäänestäjinä (naisten osuus äänioikeutetuista on noin 60\%) ei osunut yhteen ihmisten toiminnan ja mielipiteiden kanssa ruohonjuuritasolla ja tämä yllätti vallanpitäjät. Samaan aikaan kun poliitikot peräänkuuluttavat korkeampia syntyvyyslukuja ja painostavat naisia "jäämään kotiin keittämään borssia" (Ousmanova 2020), sukupuolisopimukset yhteiskunnassa ovat muuttumassa. Perheestä on tulossa vähemmän hierarkkinen instituutio, ja naisten emansipaatio levää kattamaan yhä uusia ihmisryhmiä. Naiset omaksuvat yhä aktiivisemman ja itsenäisemmän roolin (systeemin asettamien rajojen puitteissa) ja heillä on "erilainen visio omista uramahdollisuuksistaan sekä käsitys omasta henkilökohtaisesta vapaudesta" (Ousmanova 2020). Paikalliset variaatiot feminismistä ja muista poliittisen aktivismin liikkeistä, kuten ympäristöliikkeestä, näyttävät tietä useiden yhtäaikaisten merkityksellisten ja kestävien horisontaalisten yhteyksien syntymiselle (Fanailova 2020). ${ }^{5}$

Seuraava merkittävä valkovenäläisten naisten näkyvää roolia protestiliikkeessä selittävä tekijä on, että naiset eivät ainoastaan toimi patriarkaatin mukaisesti, vaan myös käyttävät patriarkaatin periaatteita sen haastamiseen. Protestit osoittivat roolien vaihtumisen kun naiset kirjaimellisesti tulivat kaduille suojaamaan miehiä omalla ruumiillaan. ${ }^{6}$ Samalla kun naiset osoittivat aktiivisempaa yhteiskunnallista toimijuutta ja tasavertaisuutta miesten rinnalla, he myös käyttivät hyväkseen patriarkaaliseen järjestelmään sisäänkirjoitettua ajatusta siitä, että poliisin erityisjoukot olisivat haluttomia vangitsemaan naisia (seuraten ajatuksia kunniakoodista, maineen tahrautumisesta ja implisiittisestä hierarkiasta, jossa miehet toimivat puolustajina ja suojelijoina heikompia naisia, lapsia tai vanhuksia kohtaan). Toisin sanoen naiset esittivät patriarkaalista "heikon" roolia systeemiä vastaan ja käyttivät sitä vallan välineenä.' Tämän lisäksi se, että naiset nähdään vähemmän uhkaavina, mahdollisti sen, että protestit kuvattiin väkivallattomina, mikä edelleen teki tyhjäksi valtion median yritykset esittää mielenosoitukset karmivina väkivaltaspektaakkelina. ${ }^{8}$ Viimeiseksi voi vielä sanoa, että valkovenäläiset naiset ovat tietoisia siitä, että yhteiskunnan 
rakenteet uusintavat sitkeästi binaarista ajattelua ja sukupuolten välistä epätasa-arvoa, että nämä näyttäytyvä monille välttämättöminä ja että naiset itsekin osallistuvat käytännön tasolla niiden uusintamiseen. He kuitenkin pystyvät reflektoimaan ja problematisoimaan näitä rakenteita luovan huumorin ja protestitaiteen keinoin. Yksi paljonpuhuva esimerkki on mielenosoituksessa käytetty juliste, jossa luki "Kyllä, minulla on ne päivät kuukaudessa - päivät vastustaa diktatuuria" (U menja "eti dni" - dni borby s diktaturoi) (Gorpichenko 2020). Toinen esimerkki samasta ilmiöstä on uudelleen käyttöön otettu toisen maailmansodan aikainen juliste, jossa teksti "Rodina-mat zovjot" (Äiti-Venäjä kutsuu!) on vaihdettu "Rodina, Mash, zavjot!" eli "Isänmaa, Masha kutsuu!" viitaten triumviraatin Maria Kolesnikovaan (Davis and Davlashyan 2020), ja kolmas "morsianten performanssi", jossa naiset tekivät valkoisista morsiuspuvuistaan vallankumouksen valko-puna-valkolippuja (Fanailova 2020). Esimerkkejä on paljon lisää ja näyttääkin, että protestitaide tarjoaa lähes loputtomat mahdollisuudet tällaisille sukupuolirooleja karnevalisoiville poliittiselle kannanotoille.

Yllä käsitellyt esimerkit ja niiden taustatekijät kuvaavat ihmisarvon vallankumousta ja naisten roolia siinä kiinnittäen erityisesti huomiota muutoksiin yksityisen ja julkisen välillä. Toisin sanoen Valko-Venäjän protestien kenties näkyvin piirre on se, että niissä yksityinen on tuotu julkisen piiriin tiettyjen päämäärien edistämiseksi. Kysymys on kuitenkin myös oikeudesta puhua ääneen, eikä vain naisena vaan myös kansalaisena, joka edustaa maata johon ylpeänä kuuluu. Se, että merkitseekö tämä naisten väliaikaista politisoitumista vai pidempiaikaista kehityskulkua osana valkovenäläisen yhteiskunnan laajempaa murrosta jää vielä avoimeksi kysymykseksi. On kuitenkin selvää jo tässä vaiheessa, että Valko-Venäjälle on syntynyt kansakunta, jossa naisista on tulossa entistä näkyvämpiä. Naiset ovat astumassa pois semiperiferiastaan ja osallistumassa kansakunnan rakentamisen monimutkaiseen prosessiin vaikuttaen sekä tulevaisuuden visioihin että jo käynnissä olevaan sosiaaliseen kehitykseen Valko-Venäjällä ja ehkä myös sen naapurimaissa.

\author{
Galina Miazhevich \\ Englannista suomentanut Jaakko Turunen
}

\title{
Viitteet
}

1 The Guardian Weekly omisti 21.8.2020 kansikuvan Valko-Venäjän protesteille kutsuen niitä "kukkaisvallaksi" ("Flower Power. The Women driving Belarus' movement for change").

2 Baginskajan muotokuvia julkaistiin Italian Voguen online-versiossa syyskuussa 2020.

3 Aleksijevitš muun muassa on pyytänyt tuen osoitusta ja solidaarisuutta merkittäviltä venäläisiltä henkilöiltä ja esimerkiksi venäläinen kirjailija Ljudmila Ulitskaja ilmaisi tukensa julkisessa lausunnossa. 
4 Nyt heitä tukevat myös merkittävät länsimaiset naisjohtajat kuten Hilary Clinton, Dalia Grybauskaite ja Vera Jurova, ks. Hartyja ' 97 (2020).

5 Olga Shparagan mukaan (joka muuten vangittiin protestien aikana) hallintokoneiston vastaus koronapandemiaan paljasti sen yhteiskuntasopimuksen joka vallitsee vakaan autoritaarisen hallintokoneiston ja ihmisen välillä: naiset hoiva-alalla kohtasivat hallinnon tuen poissaolon (Fanailova 2020).

6 Tämän voi myös tulkita itseuhraavaksi toimeksi. Tosin nyt naiset uhrasivat itsensä yksityiselämän piirin sijaan julkisessa tilassa ja patriarkaatin yhdessä murtumakohdassa, jossa jotkut miehet ovat vallassa mutta toisen miehet ovat vallan hylkäämiä ja heikkoja ja tarvitsevat suojelua. Tilanteessa, jossa valtio hylkää roolinsa kansalaisten suojelijana ja yhteiskuntasopimuksen vartijana, naisilla ei ollut muuta mahdollisuutta kuin luottaa itseensä (Walker 2020).

7 Protestien jatkuessa myös naisia alettiin ottaa kiinni huolimatta siitä ovatko he nuoria, vanhoja tai näkyvästi raskaina.

8 Naiset myös näkyivät useammin valkovenäläisissa vaihtoehtomedioissa sekä kansainvälisessä mediassa tuoden esiin moninaisia kuvia ja ilmauksia uhmakkuudesta vihaan ja epätoivoon.

\section{Lähteet}

AFP (2020), Belarus Opposition Trio Nominated For 2021 Nobel Peace Prize, Agence France Presse, 18.10., https://www.barrons.com/news/belarus-opposition-trio-nominated-for-2021-nobel-peaceprize-01603029304?tesla=y (Tarkistettu 24.11.2020).

Blagojevic-Hjuson, M. (2014) Transformation of parenthood: The semiperipheral perspective, Sociologija 56:4, 383-402, DOI: 10.2298/SOC1404383B.

Bush, D. (2020). No Modest Voices: Social Media and the Protests in Belarus, Stanford Internet Observatory, 28.8., https://cyber.fsi.stanford.edu/io/news/no-modest-voices-social-media-andprotests-belarus (Tarkistettu 24.11.2020).

Davis, S. and Davlashyan N. (2020), Soviet WWII propaganda revised to hail detained Belarus opposition figure Maria Kolesnikova, Euronews, 10.9, https://www.euronews.com/2020/09/10/ soviet-wwii-propaganda-revised-to-hail-detained-belarus-opposition-figure-maria-kolesnikov (tarkistettu 24.11.2020).

Fanailova, E. (2020). "Avtoritarism-ne takaya prostaya shtuka. Belarus i zhenskii protest", Svoboda.org, https://www.svoboda.org/a/30847487.html?fbclid=IwAR04WGCt6sPB-fuyJj029P8oIvhGSO1ffANeTyfEOuJW2hVGBQcQ_T-mnnM (tarkistettu 24.11.2020).

Frisken, Amanda (2000). Sex in politics: Victoria Woodhull as an American public woman, 1870-1876. Journal of Women's History 12:1: 89-111.

From Silence to Voice (2020): The 2020 Women's Protest, webinar, https://www.facebook.com/ events $/ 981459485688816 /$ ?post $\mathrm{id}=987276888440409 \&$ acontext $=\% 7 \mathrm{~B} \% 22$ source $\% 22 \% 3 \mathrm{~A} \% 2$ $229 \% 22 \% 2 \mathrm{C} \% 22$ ref_notif_type $\% 22 \% 3 \mathrm{~A} \% 22$ admin_plan_mall_activity $\% 22 \% 2 \mathrm{C} \% 22$ action_hi story\%22\%3A\%22null\%22\%7D\&notif_id=1603367573277876\&notif_t=admin_plan_mall_ activity\&ref=notif22/10/2020 (tarkistettu 24.11.2020).

Gapova E. (2020). "Svetlana Tikhanovskaya ot lichnogo k politicheskomu", Open democracy, https:// www.opendemocracy.net/ru/tikhanovskaya-ot-politcheskogo-lichnomy/ (Tarkistettu 24.11.2020).

Gorpichenko A. (2020). Interview with Olga Romanova, https://povaha.org.ua/da-u-menya-ety-dnydny-borbyi-s-dyktaturoj-yntervyu-pro-femynyzm-protestyi-y-zhyzn-v-belarusy/?fbclid=IwAR2jnRYdzBalSd1y_X35LrYLizLfYnzUcZNzKEi6XWEgRoVA5v3hnfZx77E (tarkistettu 24.11.2020).

Hartyja ' 97 (2020), "Clinton, Grybauskaite And Yurova Supported Belarusian Protests", 23.10. Hartyja '97 -nettisivusto, https://charter97.org/en/news/2020/10/23/397954/ (Tarkistetttu 3.12.2020) 
Herasimenka, A., Lokot, T., Onuch O. and M. Wijermars (2020). There is more to Belarus's 'Telegram revolution', The Washington Post, 11.9.

Katz, M (2020). Women as a symbol of protest-Belarus and other examples. Youtube, https://www. youtube.com/watch?v=Bf97g1ZTCYg (tarkistettu 24.11.2020).

O'Loughlin J., Toal, G. and Bakke, K. (2020) Is Belarus in the middle of a generational upheaval? Global Voices, 17.9., https://globalvoices.org/2020/09/17/is-belarus-in-the-midst-of-a-generationalupheaval/?fbclid=IwAR3_YY3ksPvrSSVPT8oFNACue93AoTAioaTxH1_i5oyhi9TanPR8WfvZzU (Tarkistettu 24.11.2020).

Ousmanova, A. (2020). Belarus 2020: Time for \#evalution, Institute for Human Sciences, https:// www.iwm.at/chronicle-from-belarus/almira-ousmanovabelarus-2020-time-for-evalution/ (tarkistettu 24.11.2020).

The PEN pod (2020). "Resisting Political Violence and Dictatorship in Belarus with Hanna Komar", The PEN Pod, 25.9., https://pen.org/the-pen-pod-hanna-komar/?fbclid=IwAR1RnBfXe8Jw2LbyUW0bavwMT-UNgXPqpISH-ILWRClb39ndtdzBn3iMIc (Tarkistettu 24.11.2020).

Walker S. (2020) We can only help ourselves: Women in Belarus take protest into their own hands, The Guardian, 14.8., https://www.theguardian.com/world/2020/aug/14/women-belarus-take-protestsinto-their-own-hands (Tarkistettu 24.11.2020). 